\title{
PENGEMBANGAN ALAT PERAGA PENGENALAN TATA SURYA BIMA SAKTI MENGGUNAKAN AUGMENTED REALITY DI PAUD
}

\author{
Budi Arifitama \\ Teknik Informatika, Universitas Trilogi \\ Jl. Kampus Trilogi /STEKPI No.1 \\ E-mail:budiarif@universitas-trilogi.ac.id
}

\begin{abstract}
PAUD (Early Child hood Education) is the beginning of a process of education given in the early stages for children, which is spread in local region based location. The purpose for the establishment of PAUD is as a means of empowering the local communities around the region in order to prepare the children before entering formal school. As for the type of activities to stimulate the balance of growth and development of physical and spiritual, moral, physical and intelligence development, as well as language and communication. Augmented Reality is used as an innovation for the learning process of the children and an alternative replacing the conventional model. This study aims to help teachers / tutors for early childhood (PAUD) in in the form of marker that utilizes augmented reality technology, to introduce the milky way solar system.

Abstrak
PAUD (Pembelajaran Anak Usia Dini) merupakan salah satu pusat pendidikan yang diberikan untuk kelompok anak usia dini, dimana biasanya tersebar di lingkungan lokasi RW setempat. Tujuan didirikanya PAUD adalah sebagai sarana pemberdayaan masyarakat setempat dalam bidang pendidikan disekitar lokasi, guna mempersiapkan anak anak tersebut sebelum masuk ke jenjang pendidikan yang lebih tinggi Adapun jenis kegiatan yang dilakukan di PAUD guna merangsang keseimbangan perkembangan dan pertumbuhan jasmani dan rohani, yaitu, perkembangan moral dan agama, perkembangan fisik, perkembanagan kecerdasan, serta bahasa dan komunikasi. Teknologi Augmented Reality digunakan dalam penelitian ini sebagai upaya untuk pemberian materi pengajaran secara lebih visual dan inovatif kepada para peserta didik dan sebagai alternatif alat peraga yang bersifat konvensional. Penelitian ini bertujuan untuk membantu para guru / pengajar PAUD dalam hal bentuk alat peraga dalam bentuk marker memanfaatkan teknologi augmented reality, untuk mengenalkan tata surya bima sakti untuk anak usia dini di PAUD POSDAYA.
\end{abstract}

Kata kunci: PAUD, alat peraga, augmented reality, tata surya

\section{PENDAHULUAN}

Pendidikan merupakan tiang punggung dan fondasi dari generasi penerus bangsa yang harus terus dijaga dan di rangsang agar mampu bersaing di lingkup nasional maupun internasional. Pendidikan yang baik adalah pendidikan yang terencana sejak usia dini sesuai dengan UU SISDISNAS No.20 tahun 2003 yang berbunyi "Pendidikan merupakan suatu usaha yang dilakukan secara sadar dan terencana untuk mewujudkan suasana dan proses pembelajaran agar peserta didik secara aktif mampu mengembangkan potensi yang ada didalam dirinya untuk memiliki kekuatan spiritual keagamaan, kepribadian yang baik, pengendalian diri, berakhlak mulia, kecerdasan,dan keterampilan yang diperlukan oleh dirinya dan masyarakat" , dimana anak berusia dini harus mendapatkan rangsangan yang tepat sesuai dengan kategori kelompok usianya dimulai dari pengenalan benda, objek dan hewan.
Penelitian ini mengambil salah satu lokasi PAUD ( Pendidikan Anak Usia Dini) yang di koordinasikan di POSDAYA binaan universitas trilogi. Hal ini disebabkan beberapa aspek, terutama karena banyaknya PAUD yang dimiliki oleh POSDAYA binaan universitas trilogi serta banyaknya siswa yang mengikuti pembelajaran di setiap PAUD yang ada menjadikan sasaran yang baik untuk pengembangan aplikasi edukasi multimedia untuk usia dini , yang diharapkan dapat membantu para pengajar dalam kegiatan proses pengajaran serta meningkatkan interaksi kepada para siswa PAUD agar belajar menjadi lebih interaktif dan menyenangkan.

Oleh karena itu, aplikasi yang dikembangkan akan menghasilkan sebuah aplikasi dan alat peraga yang dapat berjalan di platform android, pada perangkat tablet ataupun smartphone, sehingga para pengajar di PAUD dapat dengan 
mudah memberikan pengajaran langsung kepada anak anak melalui aplikasi yang sudah ditanamkan pada perangkat masing masing.

Pengembangan aplikasi ini menggunakan metode pengembangan perangkat lunak model Waterfall dan Augmented Reality sebagai bagian dari pengembangan aplikasi ,

Menurut S, Rosa A. dan M. Shalahuddin dalam Rekayasa Perangkat Lunak (2013) Metode waterfall digunakan dengan membagi tahapan tahapan pengembangan sebagai berikut yaitu tahap analisis, perancangan, implementasi, dan ujicoba. Pada tahap ujicoba, pengujian dilakukan dengan melakukan pengujian di sisi struktural dan fungsional, sehingga pada akhirnya, aplikasi ini siap digunakan.

Augmented Reality adalah sebuah istilah yang digunakan untuk menggambarkan penggabungan antara dunia nyata dan dunia maya/virtual yang seolah olah batas antara keduanya menjadi tidak ada.

Teknologi ini telah ada sudah sejak 40 tahun yang lalu, setelah diperkenalkan aplikasi Virtual Reality (VR). Pada saat itu, penelitian-penelitian teknologi yang dilakukan ditujukan untuk aspek hardware. Head-Mounted Display (HMD) dimana sebuah perangkat seperti helm diletakan di kepala sehingga dapat melihat dunia virtual ,dimana pada saat itu merupakan satusatunya peralatan dasar dalam teknologi terbaru. Dengan berjalannya waktu, Augmented Reality berkembang dengan baik sehingga memungkinkan pengembangan aplikasi ini di berbagai bidang termasuk pendidikan.

Menurut Ronald Azuma (1997) mendefinisikan Augmented Reality sebagai sistem yang memiliki karakteristik sebagai berikut:

- Menggabungkan lingkungan nyata dan virtual

- Berjalan secara interaktif dalam waktu nyata

- Integrasi dalam tiga dimensi (3D).

Tujuan dari Augmented Reality adalah menggabungkan objek maya /tidak nyata dan realita sesungguhnya lalu dapat disatukan ke dalam satu ruang lingkup agar saling berinteraksi satu dengan lainnya sehingga batas antara keduanya seakan tidak ada.

Augmented Reality saat ini sudah mulai banyak diterapkan di berbagai bidang, seperti di dunia kesehatan sebagai alat peraga untuk keperluan medis (Indrawaty Youllia, 2013), pendidikan sebagai media pembelajaran interaktif, militer sebagai permodelan prototipe alat tempur, penggabungan teknologi augmented reality dengan barcode sebagai sarana untuk menampilkan harga barang dari sebuah produk (Wahyutama Febrian,2013) serta tidak menutup kemungkinan untuk dikembangkan pada bidang bidang lainnya.

Aplikasi ini diharapkan dapat meningkatkan rangsangan informasi untuk pengenalan tata surya dengan menggunakan media augmented reality sebagai peraga kepada anak usia dini.

\section{METODOLOGI}

Sebagai upaya penyelesaian permasalahan dari penelitian, metode yang digunakan dalam menyelesaikan permasalahan adalah menggunakan metode waterfall dan metode augmented reality.

Waterfall atau sering juga disebut air terjun adalah sebuah metode dalam pengembangan sistem yang dilakukan untuk membuat pengembangan pada aplikasi yang sedang dirintis , maupun pembaruan pada sistem yang sedang berjalan. Menurut Buku Rosa Metode pengembangan sistem merupakan proses mengembangkan atau mengubah suatu sistem perangkat lunak dengan menggunakan metodemetode atau model-model yang digunakan orang untuk mengembangkan sitem-sistem perangkat lunak sebelumnya dengan memiliki alur hidup perangkat lunak secara sekuensial atau terurut dimulai dari analisis, desain, pengodean, pengujian, dan tahap pendukung . Berikut adalah gambaran dari alur waterfall.

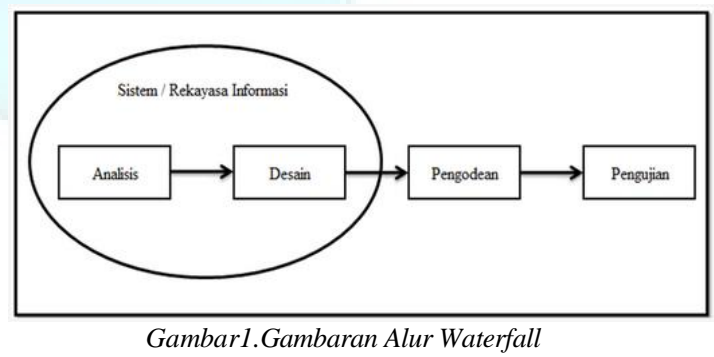

Analisis atau analisa ini merupakan tahap awal yang dilakukan oleh peneliti dalam mengembangkan sistem. Pada tahapan ini peneliti diharapkan mendapatkan informasi yang dibutuhkan sesuai dengan yang diperlukan seperti,: mencari permasalahan yang ada, mengumpulkan data (data fisik, non fisik), wawancara dan lain-lain. Dalam tahap awal ini pengembang aplikasi diharuskan melakukan penelitian yang terarah dan sesuai dengan target yang ingin dicapai.

Untuk menentukan titik permasalahan peneliti harus memilih terlebih dahulu permasalahan 
umumnya misalkan multimedia, yang kemudian dari permasalahn umum dibagi menjadi sub sub kecil seperti multimedia harus memiliki gambar, audio, teks, objek3d dan lain lain

Desain yang dimaksud bukan hanya tampilan atau interface saja, tetapi yang dimaksud desain dalam metode ini adalah desain sistem yang meliputi : alur kerja sistem, cara pengoprasian aplikasi, output dengan menggunakan metodemetode seperti perancangan tampilan sistem yang telah disesuaikan dengan analisis kebutuhan pada tahap awal untuk menyelesaikan permasalahan tersebut. Sehingga programer atau pihak yang terlibat dalam pembuatan kode program akan dipermudah karena sudah terarah seperti apa sistem ini akan berjalan dan seperti apa alur yang ada didalam sistem maupun diluar sistem.

Bagian pengkodean merupakan bagian para programmer untuk memasukan script kode pemrograman kedalam sebuah software programming untuk menghasilkan aplikasi yang telah di desain, software programming yang dapat digunakan harus disesuaikan dengan desain sistem yang dibuat (misal : untuk ponsel, Desktop, Website, dan lain-lain).

Tahap pengujian ini adalah tahap pengujian akhir dari proses siklus pengembangan sistem, ia merupakan garis akhir sebelum aplikasi dapat dikatakan layak untuk beredar untuk umum,

\section{PEMBAHASAN}

Penggunaan teknologi augmented reality sebagai inti dari teknologi yang diterapkan pada alat peraga, sehingga terdapat 2 bagian aplikasi yang harus dibuat yaitu marker sebagai landasan tempat lokasi munculnya augmented reality dan aplikasi mobile dengan isi konten tata surya bima sakti.

\subsection{Analisis Kebutuhan Sistem}

Tahapan analisis sistem dilakukan sebagai upaya awal untuk melihat sistem seperti apa yang ingin dikembangkan dengan memanfaatkan teknologi augmented reality. Didapatkan beberapa fitur yang akan di kembangkan pada aplikasi yaitu :

1. Menampilkan objek 3d berbentuk benda luar angkasa planet dan matahari

2. Suara audio penjelasan tiap planet

3. Marker sebagai alat peraga.

Berikut pada gambar adalah ilustrasi dari sistem yang akan di bangun

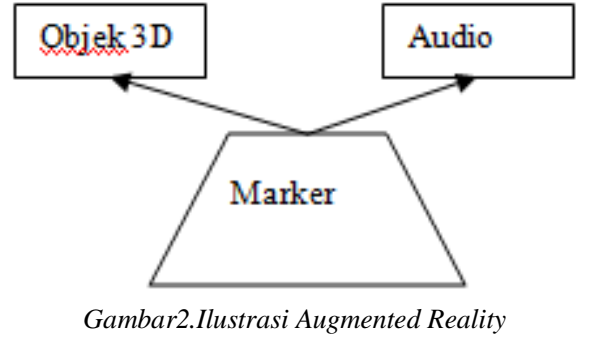

Berdasarkan ilustrasi pada gambar, penggunaan marker sebagai titik lokasi objek 3d akan teraugmented, serta audio untuk yang akan digunakan sebagai penjelasan planaet dan benda langit,

\subsection{Spesifikasi Kebutuhan Sistem}

Tahapan spesifikasi kebutuhan sistem adalah tahapan dalam hal penentuan kebutuhan perangkat lunak dan perangkat keras yang dibutuhkan dalam pengembangan aplikasi, adapun spesifikasi adalah sebagai berikut :

1. Vuforia Qualcomm sebagai pembuatan target marker

2. Unity3d sebagai platform pengembangan aplikasi

3. Smartphone atau tablet dengan android minimal versi ICS 4.1.3

\subsection{Perancangan Marker}

Perancangan marker pada aplikasi menggunakan vuforia dari qualcomm sebagai alat untuk melihat ketepatan dan keakuratan marker agar dapat digunakan sebagaimana mestinya.

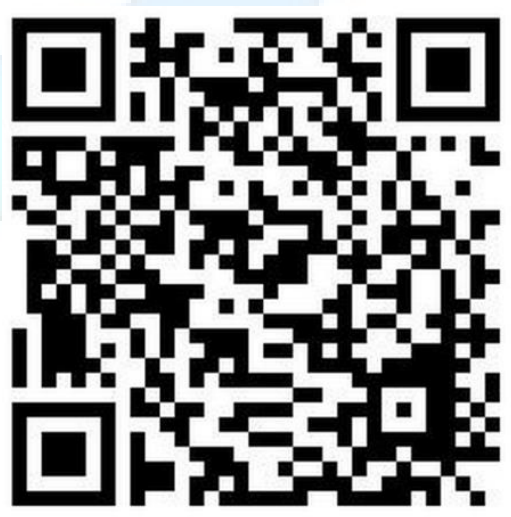

Gambar 3.Marker Augmented Reality

Pada Gambar 3, dapat dilihat marker yang digunakan adalah dalam bentuk barcode, barcode digunakan pada marker karena bentuk dan pola marker memiliki keunikan pola sehingga memudahkan dalam diferensiasi dengan pola lainnya sehingga, khusus pola barcode pada gambar 3 yang dapat memunculkan augmented reality. Hal ini diperkuat oleh hasil yang didapatkan pada gambar 3 melalui vuforia yang menyatakan bahwa marker dengan pola seperti gambar 4 dapat diterapkan augmented reality 
Arifitama, Pengembangan Alat Peraga Pengenalan Tata Surta Bima Sakti..

dengan nilai 5 dari 5 .

Type: Single Image

Status: Active

Target ID: 511a38fe2c264efobd659f9a99051412

Augmentable:

Added: Oct 24, 2014 08:25

Modified: Oct 24, 2014 08:25

Gambar 4.Nilai Marker Barcode

\subsection{Perancangan Scene_Utama Aplikasi Tata Surya}

Sebelum memulai masuk pembahasan perancangan scene_utama, adapun dapat dilihat keseluruhan scene yang akan dibangun pada tabel di bawah ini.

Tabel 1. Scene Umum Aplikasi

\begin{tabular}{|l|l|l|}
\hline No & Scene & Keterangan \\
\hline 1 & Scene_utama & Bima sakti \\
\hline 2 & Scene_matahari & Matahari \\
\hline 3 & Scene_merkurius & Merkurius \\
\hline 4 & Scene_Venus & Venus \\
\hline 5 & Scene_bumi & Bumi \\
\hline 6 & Scene_mars & Mars \\
\hline 7 & Scene_Jupiter & Jupiter \\
\hline 8 & Scene_saturnus & Saturnus \\
\hline 9 & Scene_uranus & Uranus \\
\hline 10 & Scene_neptunus & Neptunus \\
\hline 11 & Scene_Simulasi & Bima sakti \\
\hline
\end{tabular}

Berdasarkan keterangan dari tabel 1, aplikasi yang akan dirancang adalah mengenai sistem tata surya bima sakti yang terdiri dari 8 planet yaitu merkurius, venus, bumi, mars, jupiter, saturnus, uranus dan neptunus, serta simulasi perputaran dari tata surya bima sakti. Berikut adalah perancangan dari scene_matahari.

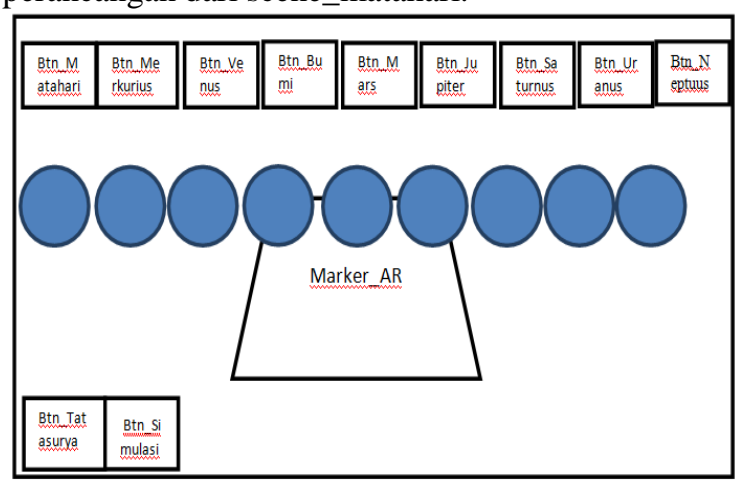

Gambar 5.Gambaran Alur Waterfall

Pada gambar 5 di atas, merupakan scene utama aplikasi ketika pertama kali dijalankan , adapun konsep augmented reality yang digunakan di sini adalah memunculkan ke delapan planet ditambah dengan matahari secara statis sesuai dengan urutan dan posisi.

Komponen yang digunakan pada gambar adalah sebagai berikut :

- Sembilan button di atas user interface yang terdiri dari buttom matahari, merkurius, venus, buni, mars, jupiter, saturnus, uranus dan neptunus.

-Dua button di bawah kiri user interface yang terdiri dari button tata_surya sebagai tombol home dan button simulasi yang digunakan untuk mensimulasikan tata surya bima sakti.

\subsection{Perancangan Scene_Matahari aplikasi tata surya}

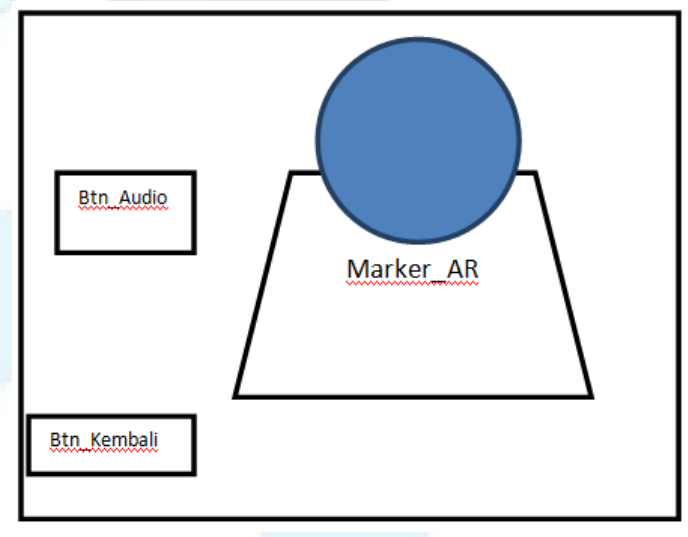

Gambar 6.Scene Matahari

Pada gambar 6 di atas, merupakan scene planet matahari dimana terdapat objek 3 dimensi matahari.

Adapun komponen yang digunakan pada gambar adalah :

-satu objek 3d matahari

-satu marker

-dua button yang terdiri dari button audio dan button kembali

-satu audio berisikan informasi matahari.

Dari kedelapan perancangan scene mengenai planet ,sama persis dengan perancangan pada gambar 6, yang membedaknya hanyalah pada audionya saja.

Adapun audio dari tiap scene planet dapat dilihat pada tabel dibawah ini.

Tabel 2. Tabel Audio dan Scene

\begin{tabular}{|l|l|l|}
\hline No & Nama_scene & Teks_audio \\
\hline 1 & Matahari & Matahari adalah sebuah \\
& & benda langit berupa bola \\
& & gas (Hidrogen dan \\
& & Helium) yang bercahaya \\
& & (berpijar). Suhu pada \\
& & permukaan matahari \\
& & sekitar 6.000 C dan suhu \\
\hline
\end{tabular}


Jurnal Sistem Informasi, Volume 5, Nomor 4, September 2015, 446-453

\begin{tabular}{|c|c|c|}
\hline & & $\begin{array}{l}\text { pada inti (bagian } \\
\text { dalam)matahari dapat } \\
\text { mencapai 15 juta derajat } \\
\text { celcius. Matahari } \\
\text { berbentuk bulat. Hal ini } \\
\text { dapat anda amati ketika } \\
\text { matahari tampakmulai } \\
\text { terbit dan terbenam. } \\
\text { Diameter Matahari lebih } \\
\text { kurang 1,4 juta km. } \\
\text { Dibandingkan dengan } \\
\text { bintang-bintang lain, } \\
\text { matahari terlihat sangat } \\
\text { besar }\end{array}$ \\
\hline 2 & Merkurius & $\begin{array}{l}\text { Planet Merkurius } \\
\text { merupakan planet yang } \\
\text { terkecil dalam tata surya } \\
\text { kita, selain itu merkurius } \\
\text { merupakan planet paling } \\
\text { dekat dengan matahari. } \\
\text { Waktu revolusi dari } \\
\text { merkurius adalah } 88 \text { hari } \\
\text { dan rotasi adalah } 59 \\
\text { hari.Planet ini mirip } \\
\text { bulan dengan kawah } \\
\text { pada dataranya dan tidak } \\
\text { memiliki satelit. Selain } \\
\text { itu , planet ini hanya } \\
\text { dapat dilihat pada subuh } \\
\text { dan maghrib }\end{array}$ \\
\hline 3 & Venus & $\begin{array}{l}\text { Venus adalah planet } \\
\text { yang terletak antara } \\
\text { merkurius dan bumi. } \\
\text { Venus merupakan planet } \\
\text { putih yang bercahaya } \\
\text { terang. Nama lain dari } \\
\text { venus adalah: } \\
\text { - Bintang fajar. } \\
\text { - Bintang timur. } \\
\text { - Bintang kejora. } \\
\text { Jarak venus dan } \\
\text { matahari adalah 108.2 } \\
\text { juta km. } \\
\text { waktu rotasi venus } \\
\text { adalah 243 hari dan } \\
\text { waktu revolusinya 224,7 } \\
\text { hari. Planet ini tidak } \\
\text { memiliki satelit . }\end{array}$ \\
\hline 4 & Bumi & $\begin{array}{l}\text { Bumi adalah satu- } \\
\text { satunya planet yang } \\
\text { memiliki kehidupan, } \\
\text { karena bumi memiliki } \\
\text { susunan gas yang terdiri } \\
\text { dari } 78 \% \text { nitrogen, } 21 \% \\
\text { oksigen dan sisanya dari } \\
\text { gas-gas lain. waktu } \\
\text { revolusi bumi adalah } \\
365,25 \text { hari dan waktu }\end{array}$ \\
\hline
\end{tabular}

\begin{tabular}{|c|c|c|}
\hline & & $\begin{array}{l}\text { rotasinya } 24 \text { jam. Planet } \\
\text { ini memiliki satelit yang } \\
\text { disebut bulan. }\end{array}$ \\
\hline 5 & Mars & $\begin{array}{lrr}\text { Mars disebut } & \text { juga } \\
\text { dengan planet } & \text { merah } \\
\text { karena jika dilihat } & \text { dengan mata } & \text { atau } \\
\text { teropong planet ini } & \text { berwarna merah. Pada } \\
\text { permukaan } & \text { mars } \\
\text { terdapat kawah-kawah } \\
\text { dengan diameter yang } \\
\text { mencapai } 200 \text { km. Suhu } \\
\text { pada permukaan mars } \\
\text { mencapai } 50-60 \text { derajat } \\
\text { celcius. Pada malam hari } \\
\text { suhunya bisa mencapai } \\
\text { minus100 } \\
\text { celcius mars memiliki } \\
\text { waktu rotasi selama } 24,6 \\
\text { jam dan waktu revolusi } \\
\text { selama } 687 \text { hari. } \\
\text { Jarak mars dengan } \\
\text { matahari adalah 247,1 } \\
\text { juta km }\end{array}$ \\
\hline 6 & Jupiter & $\begin{array}{l}\text { Di masa Romawi kuno, } \\
\text { Jupiter dikenal sebagai } \\
\text { raja langit. Karena } \\
\text { ukurannya yg sangat } \\
\text { besar maka nama Jupiter } \\
\text { sangat sesuai untuk } \\
\text { planet ini.Diameter } \\
\text { planet ini adalah } \\
142.984 \text { km. Jarak } \\
\text { Jupiter ke matahari } \\
\text { adalah } 778 \text { juta km. } \\
\text { Waktu revolusi planet } \\
\text { ini adalah } 11,9 \text { tahun dan } \\
\text { waktu rotasinya adalah } 9 \\
\text { jam } 55 \text { menit. Atmosfer } \\
\text { Jupiter terdiri dari } \\
\text { hidrogen dan helium } \\
\text { yang memiliki ketebalan } \\
\text { seribu km dan tidak ada } \\
\text { batas yang jelas antara } \\
\text { atmosfer } \\
\text { permukaan. }\end{array}$ \\
\hline 7 & Saturnus & $\begin{array}{l}\text { Saturnus merupakan } \\
\text { planet terbesar kedua } \\
\text { setelah jupiter. Planet ini } \\
\text { termasuk planet yang } \\
\text { indah untuk dipandang, } \\
\text { dikarenakan adanya } \\
\text { cincin yang } \\
\text { melingkarinya. Cincin } \\
\text { yang mengitari Saturnus } \\
\text { terdiri dari bongkahan es } \\
\text { dan kerikil yang dilapisi } \\
\text { es. }\end{array}$ \\
\hline
\end{tabular}




\begin{tabular}{|c|c|c|}
\hline & & $\begin{array}{l}\text { Diameter planet ini } \\
120.536 \mathrm{~km} \text { dan jarak ke } \\
\text { matahari } 1.426 \text { juta km, } \\
\text { Kala revolusi } 29,5 \text { tahun } \\
\text { dan kala rotasi } 10,7 \text { jam. } \\
\text { Saturnus memiliki } 18 \\
\text { satelit dan yang terbesar } \\
\text { bernama Titan. }\end{array}$ \\
\hline 8 & Uranus & $\begin{array}{l}\text { Planet ini ditemukan } \\
\text { oleh Wilhelm Herschell } \\
\text { pada tahun } 1781 \text { di } \\
\text { Inggris. waktu revolusi } \\
84 \text { tahun dan waktu } \\
\text { rotasinya } 17 \text { jam. Planet } \\
\text { ini berwarna hijau } \\
\text { kebiru-biruan. }\end{array}$ \\
\hline 9 & Neptunus & $\begin{array}{l}\text { Neptunus adalah planet } \\
\text { terberat ke-3, terbesar } \\
\text { ke-4 dan terkeras ke-5 di } \\
\text { tata surya. Diameter } \\
\text { neptunus mencapai } \\
49,528 \text { Km. berotasi } \\
\text { selama } 16 \text { jam } 6 \text { menit } \\
\text { dan revolusinya selama } \\
\text { 164,8 ttahun. } \\
\text { Neptunus ditemukan } \\
\text { berdasarkan perhitungan } \\
\text { matematika oleh Urbain } \\
\text { le Verrier dan John } \\
\text { Couch Adams dari } \\
\text { Perancis. Dan akhirnya } \\
\text { pada } 23 \text { September } 1846 \\
\text { Johann Gotfried Gale } \\
\text { dari Jerman menemukan } \\
\text { planet ini. Struktur } \\
\text { Neptunus sangat mirip } \\
\text { dengan Uranus, oleh } \\
\text { karena itu planet ini } \\
\text { sering disebut sebagai } \\
\text { "saudara kembar" } \\
\text { Uranus. }\end{array}$ \\
\hline
\end{tabular}

\subsection{Perancangan Scene_Simulasi Aplikasi Tata Surya}

Berikut adalah gambar perancangan scene_simulasi

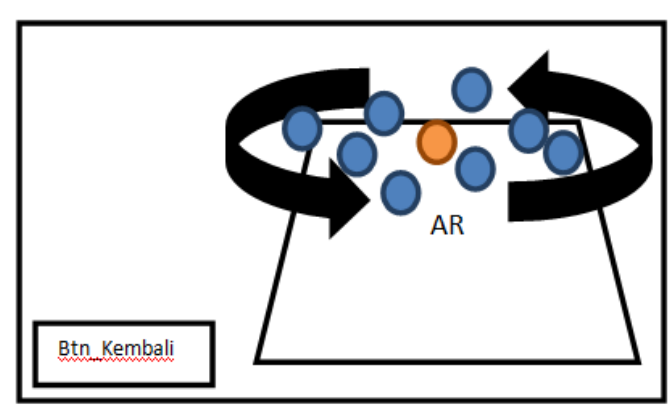

Gambar 7.Simulasi Tata Surya

Pada gambar 7 di atas, merupakan scene simulasi bima sakti dimana terdapat objek 3dimensi planet dan matahari .

Adapun komponen yang digunakan pada gambar adalah :

- 9 objek 3d (matahari, merkurius, venus, bumi, mars, jupiter, saturnus, uranus, neptunus)

- satu marker

- satu button yang terdiri dari button audio dan button kembali

\subsection{Implementasi}

Pada bagian ini, akan dijelaskan mengenai implementasi secara koding dan implementasi penggunaan dari aplikasi alat peraga tata surya menggunakan augmented reality. Adapun source code dari user interface dapat dilihat pada gambar di bawah ini,

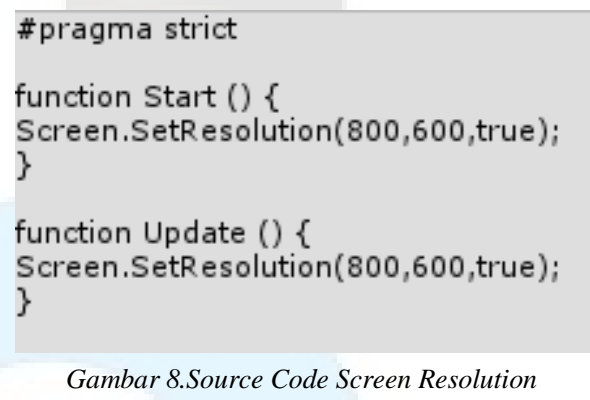

Pada gambar 8, adalah koding mengenai resolusi dari aplikasi agar dapat dijalankan pada jenis resolusi pada perangkat yang berbeda.

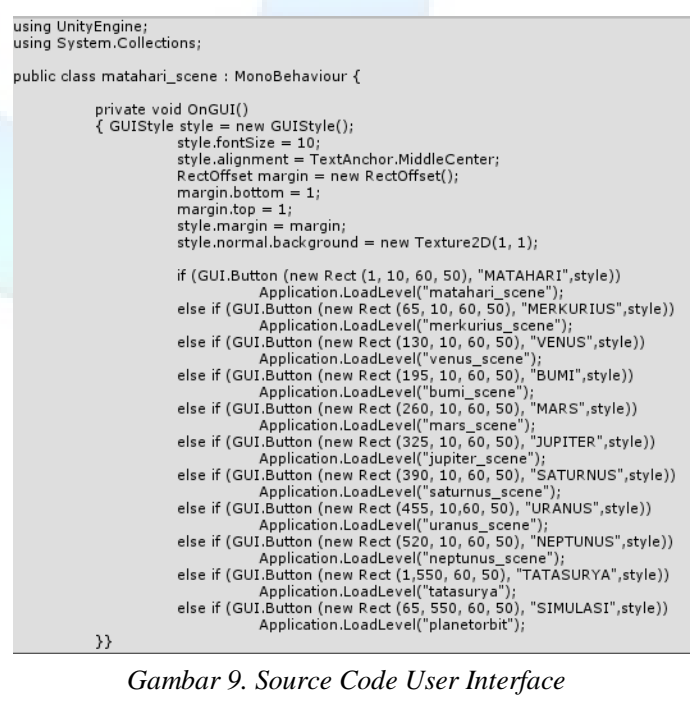

Pada gambar 9, adalah koding mengenai tata letak dari GUI tombol yang akan menghubungkan dari satu scene ke scene lainnya.

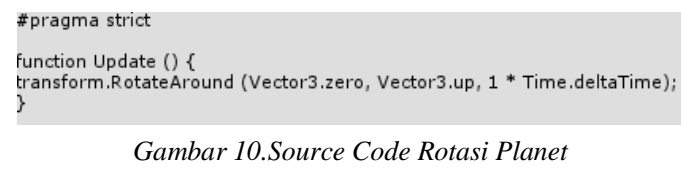

\section{Gambar 10.Source Code Rotasi Planet}

Pada gambar 10, adalah koding mengenai rotasi objek planet dengan memanfaatkan method 
transform dan rotate.

Implementasi dari aplikasi tata surya dilaksanakan dengan cara pertama, yaitu melakukan scan kepada marker yang telah disediakan, lalu akan muncul objek $3 \mathrm{~d}$ augmented reality dengan objek 1 matahari dan 8 planet dari tata surya bima sakti seperti pada gambar 7 .

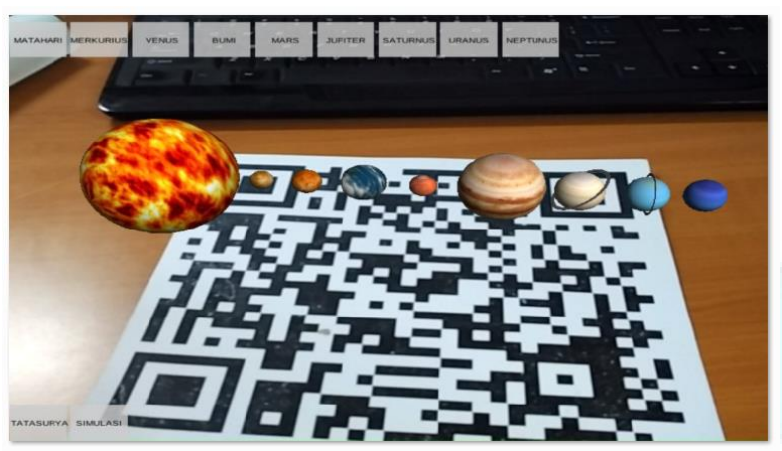

Gambar 11. Menu Tata Surya

Setelah masuk menu utama, maka tekan button matahari untuk masuk pada scene matahari seperti pada gambar 12 .

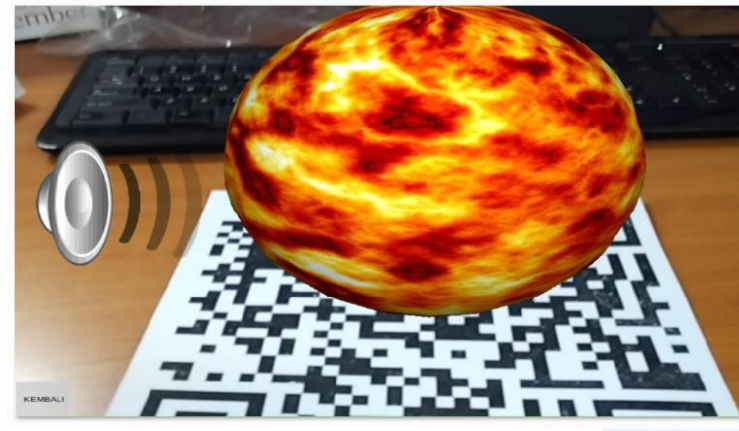

Gambar 12.Menu matahari

Pada gambar 12 , marker akan memperlihatkan objek matahari dalam bentuk $3 \mathrm{~d}$ dan augmented reality, audio dipergunakan sebagai media informasi pengenalan matahari.

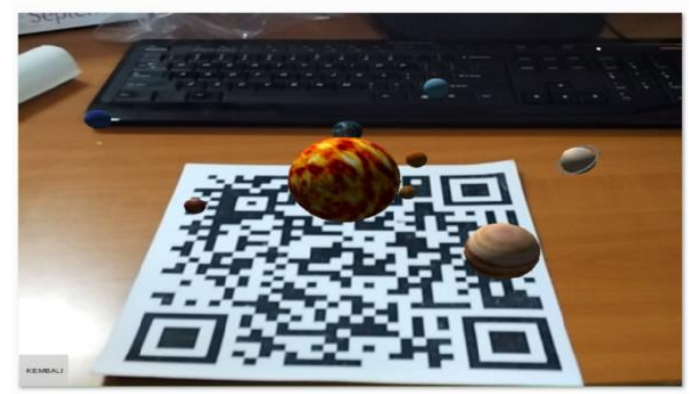

Gambar 13.Menu Simulasi

Gambar 13, merupakan scene dari simulasi, pada scene ini yang tejadi adalah ketika pengguna melakukan scan pada marker, objek 3d planet dan matahari akan mensimulasikan rotasi dari tata surya bima sakti.

\subsection{Pengujian Aplikasi}

Pada bagian ini akan dijelaskan pengujian dilakukan terhadap fungsionalitas dengan berbagai test case. Pengujian ini dimaksudkan untuk memasitikan bahwa aplikasi yang dibuat sudah sesuai dengan yang diinginkan. Berdasarkan hasil uji, terdapat satu scene simulasi yang digambarkan pada gambar 14, dimana waktu rotasi dari tiap benda langit tidak sesuai dengan waktu riil rotasi .

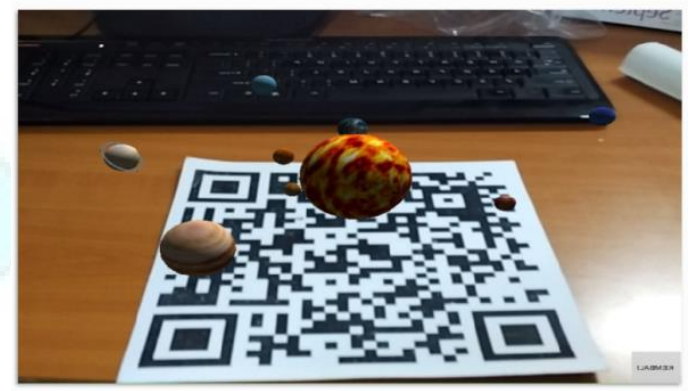

Gambar 14. Rotasi Waktu Simulasi

\section{KESIMPULAN}

Berdasarkan penelitian yang telah dilakukan, didapatkan kesimpulan yang dapat disimpulkan menjadi beberapa poin, yaitu :

1. Pada penelitian ini digunakan augmented reality sebagai inovasi dari alat peraga tata surya bima sakti

2. Marker dengan barcode mendapatkan rating yang baik untuk marker, yaitu 5 dari 5 baik .

Berdasarkan pada penelitian yang telah dilakukan, maka saran penulis terhadap peneltian selanjutnya adalah sebagai berikut :

1. Animasi dab informasi yang lebih interaktif dari setiap planet

2. Waktu perputaran tata surya yang sama dengan keadaan riil pada saat simulasi.

\section{DAFTAR RUJUKAN}

Indrawaty Youllia, Ichwan M, Putra Wahyu, "Media Pembelajaran Interaktif Pengenalan Anatomi Manusia Menggunakan Metode Augmented Reality”, Jurnal Informatika Universitas Teknologi Nasional Bandung, ,no 2, vol 4 (2013)

Wahyutama Febrian, Samopa Febriliyan, Suryotrisongko Hatma "Penggunaan Teknologi Augmented Reality Berbasis Barcode sebagai Sarana Penyampaian Informasi Spesifikasi dan Harga Barang yang Interaktif Berbasis Android, Studi Kasus pada Toko 
Arifitama, Pengembangan Alat Peraga Pengenalan Tata Surta Bima Sakti..

Elektronik ABC Surabaya",JURNAL TEKNIK POMITS Vol. 2, No. 3, (2013)

Republik Indonesia. 2003. UU SISDISNAS No.20 tahun 2003, tentang sistem pendidikan nasional.

S, Rosa A. dan M. Shalahuddin . Rekayasa Perangkat Lunak.Bandung Informatika . 2013

Azuma, Ronald.1997.“A Survey of Augmented Reality”.CA : Hughes Research Laboratory 